\title{
Net Ecosystem Production (NEP) of the Great Plains, United States
}

\author{
Daniel Howard, Tagir Gilmanov, Yingxin Gu, Bruce Wylie, Li Zhang
}

\section{Introduction}

Gross primary production (GPP) and ecosystem respiration $(\mathrm{Re})$ are the fundamental environmental characteristics that promote carbon exchanges with the atmosphere (Chapin and others, 2009), although other exchanges of carbon, such as direct oxidation (Lovett and others, 2006), can modify net ecosystem production (NEP). The accumulation of carbon in terrestrial ecosystems results in systems in which soil organic matter (SOM) carbon often exceeds biomass carbon (Post and Kwon, 2000). This SOM pool exists at a steady state between GPP and Re in ecosystems unless drivers change or the ecosystem endures environmental perturbations (for example, climatic). As indicated by Wilhelm and others (2011), conversion of grasslands to agriculture and cultivation can result in reduced soil carbon, with the release of carbon dioxide $\left(\mathrm{CO}_{2}\right)$ to the atmosphere by stimulated oxidation and higher Re; therefore, land-use and land management practices have clear effects on NEP, with potential repercussions on ecosystems. The recent demand for biofuels has changed land-use and cropping patterns, especially in Midwestern United States (Wilhelm and others, 2011). It is important to ensure the sustainability of these and other land uses and to assess the effects on NEP.

Flux tower networks, such as AmeriFlux and FLUXNET, consist of a growing number of eddy covariance flux tower sites that provide a synoptic record of the exchange of carbon, water, and energy between the ecosystem and atmosphere at various temporal frequencies. These towers also detect and measure certain site characteristics, such as wind, temperature, precipitation, humidity, atmospheric pressure, soil features, and phenological progressions. Efforts are continuous to combine flux tower network data with remote sensing data to upscale the conditions observed at specific sites to a regional and, ultimately, worldwide scale. Data-driven regression tree models have the ability to incorporate flux tower records and remote sensing data to quantify exchanges of carbon with the atmosphere (Wylie and others, 2007; Xiao and others, 2010; Zhang and others,
2010; Zhang and others, 2011). Previous study results demonstrated the dramatic effect weather has on NEP and revealed specific ecoregions and times acting as carbon sinks or sources. As of 2012, more than 100 siteyears of flux tower measurements, represented by more than 50 individual cropland or grassland sites throughout the Great Plains and surrounding area, have been acquired, quality controlled, and partitioned into gross photosynthesis $(\mathrm{Pg})$ and ecosystem Re using detailed light-response, soil temperature, and vapor pressure deficit (VPD) based analysis.

\section{Study Area}

As shown in figure 1, the Great Plains is a vast expanse located in the central United States where 73 percent of the total surface area is grassland (36 percent) or cropland (37 percent). The Great Plains is an agriculturally intensive region where sustainable land management is necessary to promote soil conservation. Major environmental and climatic conditions in the Great Plains have clear spatially relative patterns that can be observed throughout historical data (Gu and others, 2012). For example, the average annual temperature generally increases from the northern Great Plains [4 degrees Celsius $\left({ }^{\circ} \mathrm{C}\right)$ ] to the south $\left(22^{\circ} \mathrm{C}\right)$ and precipitation increases from the western Great Plains [200 millimeters $(\mathrm{mm})]$ to the east $(1,500 \mathrm{~mm})$.

\section{Grassland NEP in the Great Plains}

Zhang and others (2011) applied regression tree modeling to incorporate grassland-specific flux tower recordings of NEP in conjunction with remote sensing, climate, phenology, and other biogeophysical data to map annual NEP of grasslands in the Great Plains at 250-meter (m) resolution for 2000-2008 (figure 2). In their results, the grasslands of the Great Plains were determined to be a net sink with an average annual NEP of 24 grams of carbon per square meter per year $\left(\mathrm{g} \mathrm{C} / \mathrm{m}^{2} / \mathrm{yr}\right)$ and a standard deviation of $14 \mathrm{~g} \mathrm{C} / \mathrm{m}^{2} / \mathrm{yr}$. Throughout the 9 -year period, the annual NEP was determined to be extremely variable, 


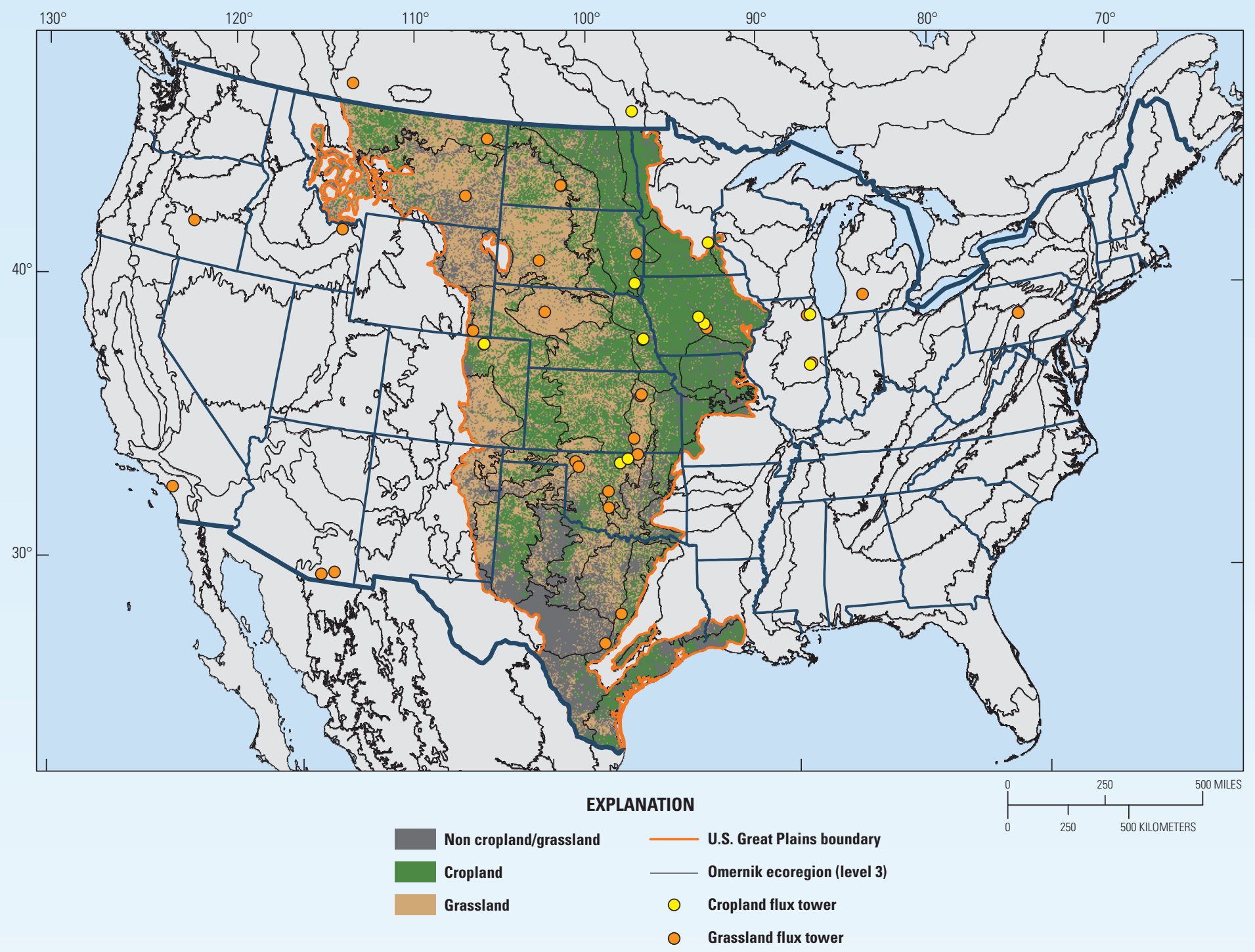

Figure 1. Flux towers, land cover, and ecoregions in the Great Plains.

ranging from a low average annual NEP of $0.3 \mathrm{~g} \mathrm{C} / \mathrm{m}^{2} / \mathrm{yr}$ in 2002 to a high value of $47.7 \mathrm{~g} \mathrm{C} / \mathrm{m}^{2} / \mathrm{yr}$ in 2005 . The results provided an account of NEP for 36 percent of the total land cover in the Great Plains.

\section{NEP Uncertainty Assessment and Site Selection and Development of Future Flux Towers}

Although there has been substantial growth in flux tower networks, the extensive cost, maintenance, and management requirements associated with keeping each individual flux tower operational has limited network development. Proper placement of new flux towers is critical for maximizing adequate representation of certain vegetation cover types, climate conditions, or biogeophysical conditions. Working directly with the model and results from Zhang and others (2011), Gu and others (2012) developed an innovative method to identify and map areas that are underrepresented by the flux tower network. The NEP model from Zhang and others (2011) was regenerated using two different limits on extrapolation
(10 percent and 50 percent). The absolute difference of weekly output from the two model versions was calculated, annually averaged, and mapped with a $250-\mathrm{m}$ resolution to assess and identify instances where the NEP model relied on heavy extrapolation (figure 3 ). In theory, a pixel that incorporated ancillary environmental input data [for example, Normalized Difference Vegetation Index (NDVI), weather, soils, and phenology] that conformed to characteristics observed at a particular flux tower and, therefore, is well represented, would be assigned a similar NEP value in the 10 percent and 50 percent extrapolation models; however, pixels that characterized a range of environmental variables that were not well represented by any flux tower in the network would have a higher likelihood to be assigned NEP values that exhibited significant differences between the 10 percent and 50 percent extrapolation models. The resulting maps from this study could provide useful information for optimizing the site selection and development of future flux towers in the Great Plains and could serve as a proxy for NEP uncertainty maps. 


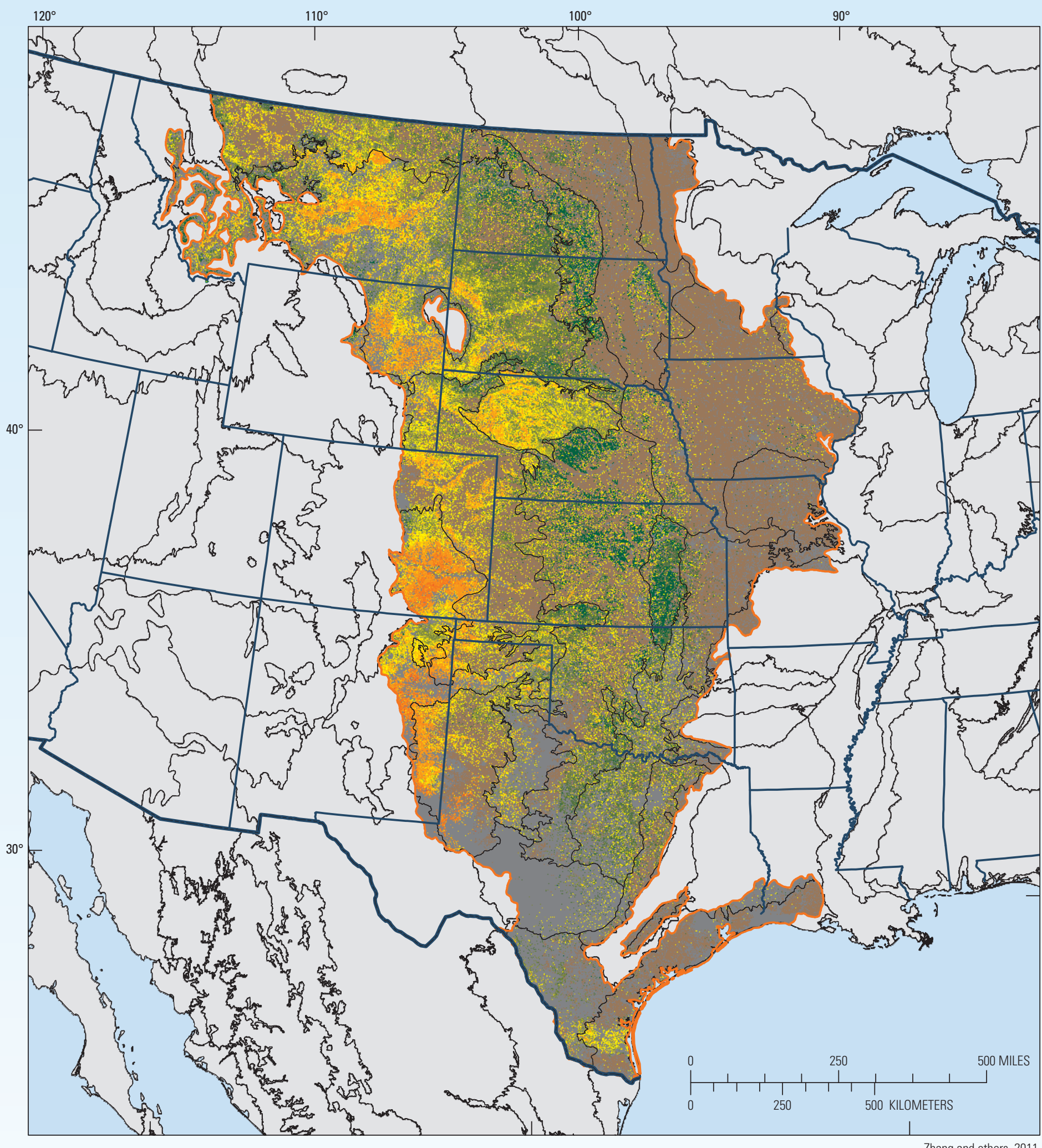

EXPLANATION

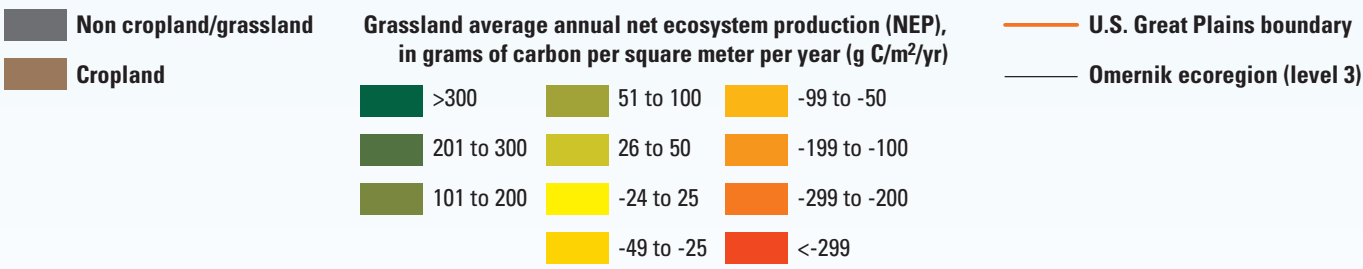

Figure 2. Average annual net ecosystem production (NEP) (2000-2008) for the grasslands of the Great Plains. 


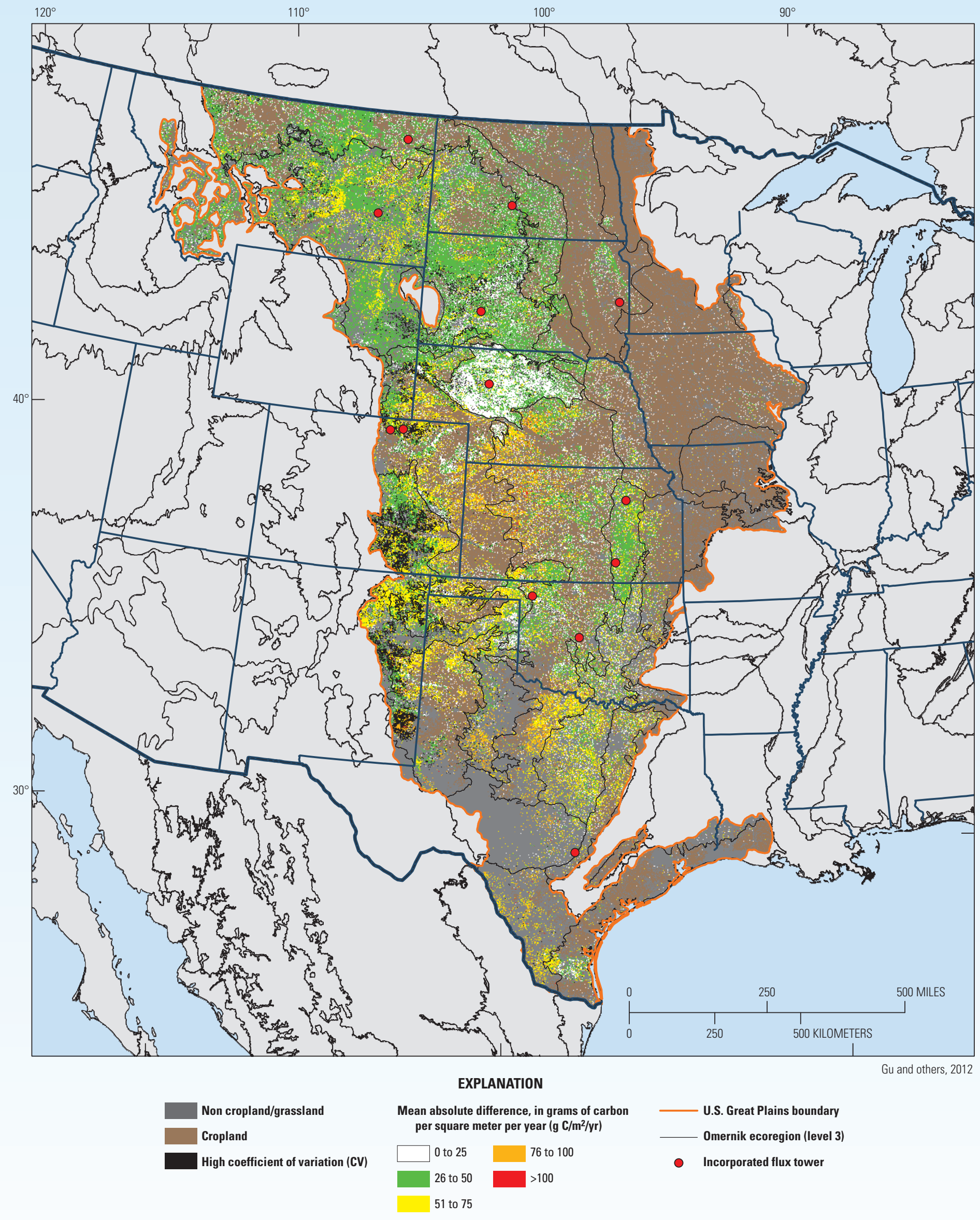

Figure 3. Average annual mean absolute difference between the two estimated NEP values ( 10 percent and 50 percent extrapolation). Areas with highest differences (yellow, orange, and red on the map) are interpreted as having low model confidence, being poorly represented by the current flux tower network, or both [excluding areas where the interannual coefficient of variation (CV) is greater than 20 percent (black area)]. 


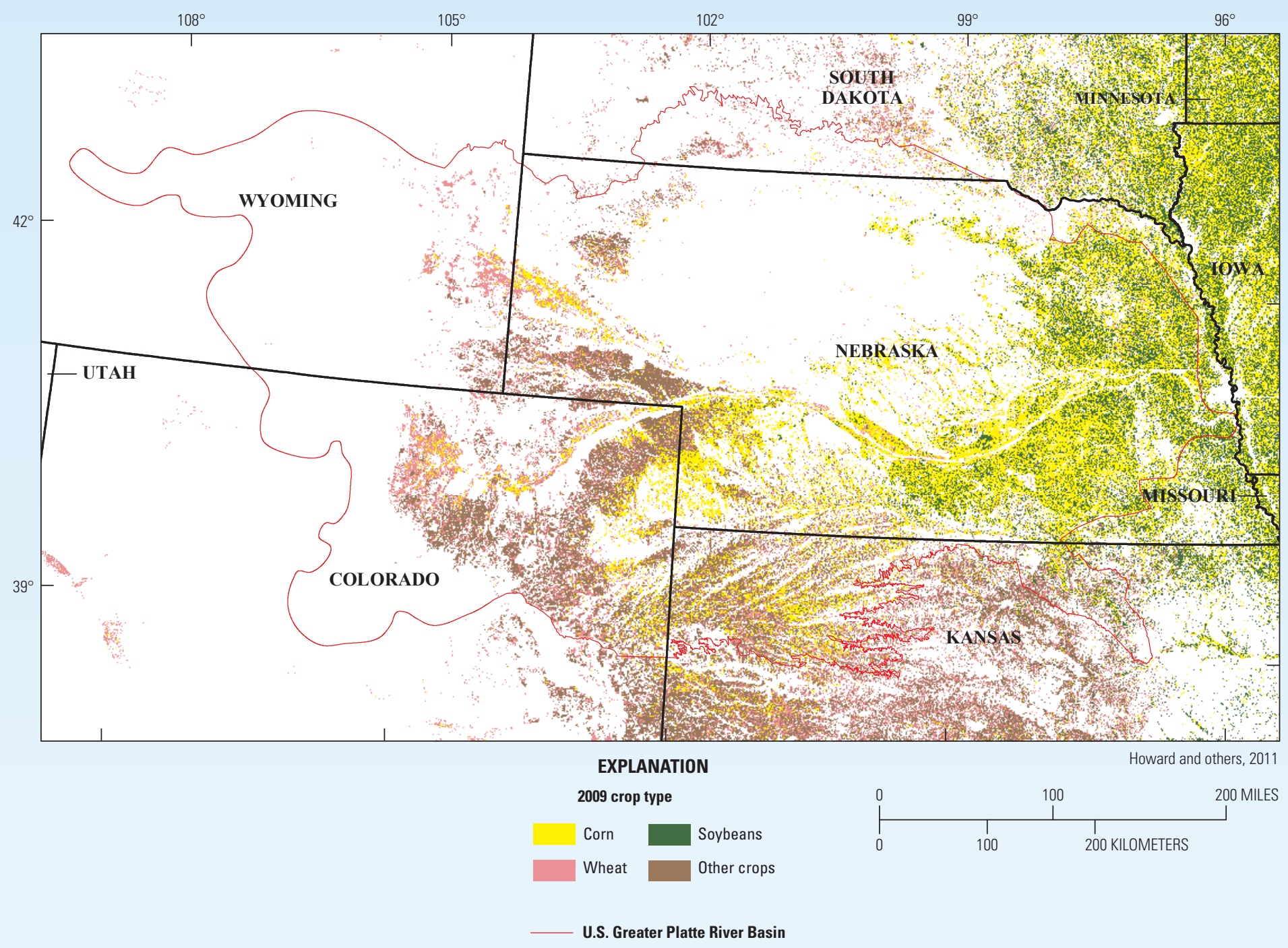

Figure 4. Spatial distribution of corn, soybeans, wheat, and other crops of the Greater Platte River Basin for 2009.

\section{Crop Type Mapping and Cropland NEP in the Great Plains}

Although grasslands account for a substantial part of the total land cover in the Great Plains, the ultimate objective is to model and quantify NEP for all major land cover types existing in the Great Plains. Croplands are the future of comprehensive NEP quantification in the region. The primary requirements for implementing NEP quantification of croplands are to develop spatially-accurate crop type classification data and a NEP algorithm for specific crop types. Howard and others (2012) developed a regression tree model based on weekly 250 -m expedited Moderate Resolution Imaging Spectroradiometer (eMODIS) NDVI composites (Jenkerson and others, 2010), in conjunction with several other environmental variables, to identify and map distinct annual crop types (for example, corn, soybeans, and wheat) of the Greater Platte River Basin during 2000-2009 (figure 4). This approach is being expanded to include additional crop types (corn, soybeans, winter wheat, spring wheat, cotton, sorghum, and alfalfa) for the entire U. S. Great Plains. Additionally, with the use of crop-sited flux towers, progress is being made towards the development of crop-specific NEP models. With the addition of cropland, 73 percent of the total land cover will be accounted for in the overall NEP quantification of the Great Plains. This quantification of carbon fluxes in cropland and grassland will provide a better understanding of the effects various vegetation types and agricultural management practices have on the net carbon balance.

\section{Acknowledgments}

This study was funded by the U.S. Geological Survey (USGS) Geographic Analysis and Monitoring Program and performed under USGS contracts G10PC00044 and G08PC91508. Any use of trade, product or firm names is for descriptive purposes only and does not imply endorsement by the U.S. Government. 


\section{References}

Chapin, F.S., III, Kofinas, G.P., and Folke, C., 2009, Principles of Ecosystem Stewardship: Resilience-Based Natural Resource Management in a Changing World (1st ed.): New York, Springer, p. 319-337.

Gu, Y., Howard, D.M., Wylie, B.K., and Zhang, L., 2012, Mapping carbon flux uncertainty and selecting optimal locations for future flux towers in the Great Plains: Landscape Ecology, v. 27 , no. 3, p. 319-326.

Howard, D.M., Wylie, B.K., and Tieszen, L.L., 2012, Crop classification modelling using remote sensing and environmental data in the Greater Platte River Basin, USA: International Journal of Remote Sensing, v. 33, no. 19, p. 6,094-6,108.

Jenkerson, C. B., Maiersperger, T.K., and Schmidt, G.L., 2010, eMODIS - A user-friendly data source: U.S. Geological Survey Open-File Report 2010-1055, 10 p. (Also available online at http://pubs.er.usgs.gov/usgspubs/ofr/ofr20101055.)

Lovett, G., Cole, J., and Pace, M., 2006, Is net ecosystem production equal to ecosystem carbon accumulation?: Ecosystems, v. 9, p. 152-155.

Post, W.M., and Kwon, K.C., 2000, Soil carbon sequestration and land-use change-Processes and potential: Global Change Biology, v. 6, p. 317-327.

Wilhelm, W.W., Johnson, J.M., Lightle, D., Karlen, D.L., Novak, J.M., Barbour, N.W., Laird, D.A., Baker, J.M., Ochsner, T.E., Halvorson, A.D., Archer, D.W., and Arriaga, F.J., 2011, Vertical distribution of corn stover dry mass grown at several US locations: BioEnergy Research, v. 4, p. 11-21.
Wylie, B.K., Fosnight, E.A., Gilmanov, T.G., Frank, A.B., Morgan, J.A., Haferkamp, M.R., and Meyers, T.P., 2007, Adaptive data-driven models for estimating carbon fluxes in the Northern Great Plains: Remote Sensing of Environment, v. 106, p. 399-413, (Also available online at http://dx.doi. org/10.1016/j.rse.2006.09.017.)

Xiao, J., Zhuang, Q., Law, B.E., Chen, J., Baldocchi, D.D., Cook, D.R., Oren, R., Richardson, A.D., Wharton, S., Ma, S., Martin, T.A., Verma, S.B., Suyker, A.E., Scott, R.L., Monson, R.K., Litvak, M., Hollinger, D.Y., Sun, G., Davis, K.J., Bolstad, P.V., Burns, S.P., Curtis, P.S., Drake, B.G., Falk, M., Fischer, M.L., Foster, D.R., Gu, L., Hadley, J.L., Katul, G.G., Matamala, R., McNulty, S.G., Meyers, T.P., Munger, J.W., Noormets, A., Oechel, W.C., Paw, U.K.T., Schmid, H.P., Starr, G., Torn, M.S., and Wofsy, S., 2010, A continuous measure of gross primary production for the conterminous United States derived from MODIS and Ameriflux data: Remote Sensing of Environment, v. 114, p. 576-591.

Zhang, L., Wylie, B.K., Ji, L., Gilmanov, T.G., and Tieszen, L.L., 2010, Climate-driven interannual variability in net ecosystem exchange in the northern Great Plains grasslands: Rangeland Ecology and Management, v. 63, no. 1, p. 40-50. (Also available online at $h t t p: / / d x$.doi.org/10.2111/08-232.1.)

Zhang, L., Wylie, B.K., Ji, L., Gilmanov, T.G., Tieszen, L.L., and Howard, D.M., 2011, Upscaling carbon fluxes over the Great Plains grasslands-Sinks and sources: Journal of Geophysical Research G - Biogeosciences, v. 116, citation number G00J03. (Also available online at http://dx.doi. org/10.1029/2010JG001504.)

For more information concerning this publication, contact:

U.S. Geological Survey Earth Resources Observation and Science (EROS) Center

47914252 nd Street

Sioux Falls, South Dakota 57198 (605) 594-6151 